\title{
Phosphorylation of endothelial NOS contributes to simvastatin protection against myocardial no-reflow and infarction in reperfused swine hearts: partially via the PKA signaling pathway
}

\author{
Xiang-dong $\mathrm{LI}^{1}$, Yue-jin YANG ${ }^{1, *}$, Yong-jian GENG ${ }^{2}$, Jing-lin ZHAO ${ }^{1}$, Hai-tao ZHANG ${ }^{1}$, Yu-tong $\mathrm{CHENG}^{3}$, Yi-ling WU ${ }^{4}$ \\ ${ }^{1}$ Department of Cardiology, State Key Laboratory of Cardiovascular Disease, Fu Wai Hospital, National Center for Cardiovascular \\ Diseases, Chinese Academy of Medical Sciences and Peking Union Medical College, Beijing 100037, China; ${ }^{2}$ The Center for Cardio- \\ vascular Biology and Atherosclerosis, Department of Internal Medicine, The University of Texas Houston Medical School, Houston, TX \\ 77030, USA; ${ }^{3}$ Department of Cardiology, Beijing An Zhen Hospital, Capital Medical University, Beijing 100029, China; ${ }^{4}$ The Integration \\ of Traditional and Western Medical Research Academy of Hebei Province, Shijiazhuang 050035, China
}

\begin{abstract}
Aim: The cholesterol-lowering drugs statins could enhance the activities of endothelial nitric oxide synthase (eNOS) and protect myocardium during ischemia and reperfusion. The aim of this study was to examine whether protein kinase A (PKA) was involved in statinmediated eNOS phosphorylation and cardioprotection.

Methods: 6-Month-old Chinese minipigs (20-30 kg) underwent a 1.5-h occlusion and 3-h reperfusion of the left anterior descending coronary artery (LAD). In the sham group, the LAD was encircled by a suture but not occluded. Hemodynamic and cardiac function was monitored using a polygraph. Plasma activity of creatine kinase and the tissue activities of PKA and NOS were measured spectrophotometrically. p-CREB, eNOS and p-eNOS levels were detected using Western blotting. Sizes of the area at risk, the area of no-reflow and the area of necrosis were measured morphologically.

Results: Pretreatment of the animals with simvastatin (SIM, $2 \mathrm{mg} / \mathrm{kg}$, po) before reperfusion significantly decreased the plasma activity of creatine kinase, an index of myocardial necrosis, and reduced the no-reflow size (from $50.4 \% \pm 2.4 \%$ to $36.1 \% \pm 2.1 \%, P<0.01$ ) and the infarct size (from $79.0 \% \pm 2.7 \%$ to $64.1 \% \pm 4.5 \%, P<0.01$ ). SIM significantly increased the activities of PKA and constitutive NOS, and increased Ser ${ }^{133}$ p-CREB protein, Ser ${ }^{1179}$ p-eNOS, and Ser ${ }^{635}$ p-eNOS in ischemic myocardium. Intravenous infusion of the PKA inhibitor $\mathrm{H}-89\left(1 \mathrm{\mu g} \cdot \mathrm{kg}^{-1} \cdot \mathrm{min}^{-1}\right)$ partially abrogated the SIM-induced cardioprotection and eNOS phosphorylation. In contrast, intravenous infusion of the eNOS inhibitor L-NNA $\left(10 \mathrm{mg} \cdot \mathrm{kg}^{-1}\right)$ completely abrogated the SIM-induced cardioprotection and eNOS phosphorylation during ischemia and reperfusion, but did not affect the activity of PKA.

Conclusion: Pretreatment with a single dose of SIM $2.5 \mathrm{~h}$ before reperfusion attenuates myocardial no-reflow and infarction through increasing eNOS phosphorylation at $\operatorname{Ser}^{1179}$ and $\operatorname{Ser}^{635}$ that was partially mediated via the PKA signaling pathway.
\end{abstract}

Keywords: heart; ischemia-reperfusion injury; no-reflow; infarction; simvastatin; H-89; L-NNA; protein kinase A; CREB; endothelial NOS

Acta Pharmacologica Sinica (2012) 33: 879-887; doi: 10.1038/aps.2012.27; published online 4 Jun 2012

\section{Introduction}

Timely reopening of the occluded coronary artery after acute myocardial infarction rescues the ischemic myocardium and reduces mortality. However, impaired regional perfusion and microvascular or endothelial dysfunction within the previously ischemic myocardium after revascularization therapy also produce the no-reflow phenomenon, which may lead

\footnotetext{
* To whom correspondence should be addressed. E-mail yangyjfw@yahoo.com.cn

Received 2011-12-28 Accepted 2012-03-05
}

to increased infarct size, contractile dysfunction, higher incidence of complications, and poor clinical outcome ${ }^{[1-4]}$. Prevention and treatment of the no-reflow phenomenon have been a worldwide challenge in this reperfusion times.

Statins are cholesterol-lowering drugs that inhibit 3-hydroxy-3-methylglutaryl coenzyme A reductase, a key enzyme in the cholesterol synthesis pathway. Previous studies have demonstrated that chronic and early pretreatment with statins can improve coronary circulation and reduce the sizes of no-reflow and infarct after ischemia-reperfusion injury by enhancing endothelial (e-)nitric oxide synthase (eNOS) activ- 
ity through the phosphatidylinositol 3-kinase (PI3K)/protein kinase B (Akt) signaling cascade $\mathrm{e}^{[4-10]}$.

According to the European Society of Cardiology (ESC) guidelines, the optimal revascularization time is within $3 \mathrm{~h}$ after the onset of acute myocardial infarction ${ }^{[11]}$. In almost all of the existing studies, statins were delivered several days before myocardial reperfusion. It is not clinically practical to pre-treat patients undergoing acute post-infarct percutaneous coronary intervention with high-dose statins several days before the procedure. In addition, recent studies have reported that the cyclic adenosine monophosphate (cAMP)/ protein kinase A (PKA) pathway plays a role in cardioprotection during ischemic preconditioning and in the cardioprotection provided by Tongxinluo, a traditional Chinese medicine ${ }^{[12-14]}$, but it is unclear whether PKA is associated with the cardioprotective effects of statins. Therefore, in this study, we tested the hypothesis that acute pretreatment with singledose statins before reperfusion exerts a cardioprotective effect against myocardial no-reflow and infarction by enhancing eNOS activity in a PKA-dependent manner.

\section{Materials and methods}

\section{Animal experimental protocols}

The animal experimental protocols and procedures were approved by the Care of Experimental Animals Committee of Fu Wai Hospital, National Center for Cardiovascular Diseases, Chinese Academy of Medical Sciences and Peking Union Medical College, China. All animals received humane care in compliance with the Guide for the Care and Use of Laboratory Animals published by the National Institutes of Health, USA.

As described previously ${ }^{[4,14]}, 6$-month-old Chinese Minipigs weighing 20 to $30 \mathrm{~kg}$ were anesthetized with a mixture of 700 $\mathrm{mg}$ ketamine hydrochloride and $30 \mathrm{mg}$ diazepam administered intramuscularly and were continuously infused with this mixture ( $2 \mathrm{mg} / \mathrm{kg}$ per hour) intravenously to maintain the anesthesia. Minipigs were assigned to 1 of 7 groups $(n=7-8$ in each group): control, simvastatin (SIM), SIM coadministered with H-89 (SIM+H-89), H-89, SIM coadministered with $N^{\omega}$-nitro-L-arginine (L-NNA; SIM+L-NNA), $L-N N A$, and sham group. All pigs except for the sham group underwent a 1.5-h occlusion and 3-h reperfusion of the left anterior descending coronary artery (LAD). The LAD of the sham animals was encircled by a suture but not occluded.

The control pigs underwent no intervention either before or after reperfusion. SIM ( $2 \mathrm{mg} / \mathrm{kg}$, Merck \& Co, USA) was gavaged $2.5 \mathrm{~h}$ before myocardial reperfusion; the SIM dosage was determined based on the loading dose $(80 \mathrm{mg})$ before acute percutaneous coronary intervention and was converted to the pig dose according to body surface area ${ }^{[15]}$. H-89 (1.0 $\mu \mathrm{g} \cdot \mathrm{kg}^{-1} \cdot \mathrm{min}^{-1}$, Alexis, USA), a PKA inhibitor, was intravenously and constantly infused throughout the procedure to inhibit PKA activity ${ }^{[13]}$. L-NNA (10 mg/kg, Aldrich, USA), an arginine derivative that can nonselectively and competitively inhibit NOS, was intravenously infused and maintained until the end of reperfusion to inhibit eNOS activity ${ }^{[16]}$. Although L-NNA inhibits both constitutive (cNOS) and inducible
(iNOS), the effect of L-NNA inhibition on cNOS is 300 fold greater than that on iNOS, and this effect is rapidly reversible. Furthermore, the predominantly expressed isoform of cNOS in the myocardium is eNOS ${ }^{[17]}$. Therefore, we chose to use L-NNA as a selective inhibitor of eNOS in the present study.

\section{Hemodynamic and cardiac function studies}

Heart rate (HR) was monitored by surface limb lead electrocardiograph. A 6F pigtail catheter was inserted into the right femoral artery though an arterial sheath for real time measurements of mean arterial pressure (MAP), left ventricular enddiastolic pressure (LVEDP), and maximum and minimum rates of left ventricular pressure development $\left(\mathrm{d} p / \mathrm{d} t_{\max }\right.$ and $\mathrm{d} p / \mathrm{d} t_{\min }$ respectively). Hemodynamic data were recorded on a polygraph (Biopac Systems, MP-150, USA) at baseline, after $1.5 \mathrm{~h}$ of ischemia, and after $3 \mathrm{~h}$ of reperfusion and analyzed with Acqknowledge v3.8.1 software.

Analysis of myocardial area at risk (AAR), area of no-reflow (ANR), and area of necrosis (AN)

Myocardial AAR, ANR, and AN were measured according to previous methods ${ }^{[4,14]}$. In brief, the area of impaired perfusion was delineated by a bolus of $4 \%$ fluorescent thioflavin $\mathrm{S}$ $(1 \mathrm{~mL} / \mathrm{kg}$, Sigma, USA) into the left atrium. Approximately 30 s later, the LAD was religated at the original site, and AAR was outlined by perfusion with a bolus of $2 \%$ Evans blue dye $(1 \mathrm{~mL} / \mathrm{kg}$, Sigma, USA) into the left atrium. The heart was then excised, and the blood was washed out. In ice-cold saline solution, the extra-left ventricular tissue was removed, and the left ventricular tissue was transversely cut into six or seven slices made parallel to the atrioventricular groove. The AAR, or the area unstained by Evans blue, was traced and pictured in visible light. The ANR, or the area not perfused by thioflavin $S$, was photographed under ultraviolet light $(365 \mathrm{~nm})$. The area between the AAR and ANR was the area of reflow (AR). Then, tissue samples were collected from ANR, AR, and nonischemic area (NA) on the reverse side of the traced slices and immediately placed in liquid nitrogen for the next examination. Finally, tissue slices were weighed and incubated in $1 \%$ triphenyltetrazolium chloride (TTC, $\mathrm{pH} 7.4$ ) at $37^{\circ} \mathrm{C}$ for $15 \mathrm{~min}$ to identify the AN. AAR was expressed as a percentage of the left ventricular mass (AAR/LV), and ANR and AN were expressed as percentages of the AAR (ANR/AAR and AN/ $A A R$, respectively), with the mass of each area determined gravimetrically.

\section{Determination of plasma creatine kinase (CK) activity}

Plasma CK activity, an index of myocardial necrosis, was measured spectrophotometrically at baseline, after $1.5 \mathrm{~h}$ of ischemia, and after $3 \mathrm{~h}$ of reperfusion according to the manufacturer's instructions (Nanjing JianCheng Bioengineering Institute, China).

\section{Tissue PKA activity assay}

PKA activity was measured according to the method described previously using a nonradioactive PKA assay kit 
(Promega, USA) ${ }^{[14,18]}$. Tissue samples from NA, AR, and ANR were homogenized on ice in PKA extraction buffer containing $25 \mathrm{mmol} / \mathrm{L}$ Tris-HCl (pH 7.4), $0.5 \mathrm{mmol} / \mathrm{L}$ EDTA, $0.5 \mathrm{mmol} / \mathrm{L}$ EGTA, $10 \mathrm{mmol} / \mathrm{L} \beta$-mercaptoethanol, $1 \mu \mathrm{g} / \mathrm{mL}$ leupeptin, and $1 \mu \mathrm{g} / \mathrm{mL}$ aprotinin. The homogenate was centrifuged at $20000 \times g$ for $5 \mathrm{~min}$ at $4^{\circ} \mathrm{C}$, and the supernatant was assayed for PKA activity according to the manufacturer's instructions. The reaction products were separated on a $0.8 \%$ agarose gel at $100 \mathrm{~V}$ for $15 \mathrm{~min}$. The phosphorylated species migrated toward the positive electrode, whereas the non-phosphorylated substrates migrated toward the negative electrode. The fluorescence intensity of the phosphorylated peptides, which reflects the PKA activity, was quantified by spectrophotometry at $570 \mathrm{~nm}$. One unit of kinase activity is defined as the number of nanomoles of phosphate transferred to a substrate per minute per milliliter.

\section{Western blotting analysis}

The expression of Ser $^{133}$ phosphorylated (pcAMP) response element-binding protein (CREB), eNOS, Ser ${ }^{1179}$ p-eNOS and Ser ${ }^{635}$ p-eNOS was detected by Western blotting, as described previously $^{[19]}$. Rabbit polyclonal p-CREB (Ser ${ }^{133} ; 1: 100$ dilution, Santa Cruz, USA), rabbit polyclonal eNOS (1:250 dilution, Cell Signaling, USA), rabbit monoclonal p-eNOS (Ser ${ }^{1179} ; 1: 250$ dilution, Invitrogen, USA), rabbit polyclonal p-eNOS (Ser ${ }^{635}$; 1:200 dilution, Upstate, USA), or mouse monoclonal $\beta$-actin (1:10000 dilution, Proteintech, USA) antibodies were applied. The immunoreactive bands were visualized using a chemiluminescence reagent. The intensity ratio of the target band to the $\beta$-actin band corresponded to the relative amounts of the target protein.

\section{Analysis of tissue NOS activity}

Tissue samples from NA, AR, and ANR were homogenized and centrifuged at $3000 \mathrm{r} / \mathrm{min}$ for $10 \mathrm{~min}$. The activity of total (t-)NOS, iNOS, and cNOS (the predominantly expressed isoform of cNOS in myocardium is eNOS ${ }^{[17]}$ ) in the supernatant was measured spectrophotometrically at $530 \mathrm{~nm}$ according to the manufacturer's instructions (Nanjing KeyGen, China). The activities were expressed as units per milligram of myocardial protein (IU/mg prot).

\section{Statistical analysis}

All data are expressed as the mean \pm SEM. Data from all stages were compared by repeated measures analysis of variance followed by post-hoc analysis with the Student-Newman-Keuls multiple comparisons test. Differences in a single variable data, such as the no-reflow and infarct areas, and the activities of PKA and NOS were compared among groups by ANOVA followed by the Duncan's post hoc test. $P<0.05$ was considered statistically significant.

\section{Results}

\section{Cardiac performance in SIM-treated and -untreated hearts}

Physiological examination revealed that there were no significant differences in cardiac hemodynamics between any of the groups at baseline $(P>0.05)$. However, under the conditions of ischemia and reperfusion, HR and LVEDP were increased in the untreated, control hearts $(P<0.05)$. The effects of ischemia and reperfusion were partially diminished when the animals received SIM pretreatment, as HR and LVEDP were decreased in the SIM group $(P<0.05)$. The effects of SIM appeared to depend on the activation of PKA and eNOS because combined treatment with SIM and the PKA inhibitor H-89 or the eNOS inhibitor L-NNA did not have the same effect as treatment with SIM alone (Table 1).

\section{Sizes of no-reflow and infarction after ischemia and reperfusion}

Pathological studies revealed that the area at risk (AAR) per left ventricle (LV) was comparable in the control, SIM, SIM+H-89, H-89, SIM+L-NNA, and L-NNA groups, averaging between $26.1 \%$ and $30.4 \%(P>0.05)$ (Figure $1 \mathrm{~A}$ and $1 \mathrm{~B})$. SIM pretreatment significantly attenuated the area of no-reflow (ANR/AAR, 36.1\% $\pm 2.1 \%$ ) and the area of necrosis (AN/AAR, $64.1 \% \pm 4.5 \%)$ compared to the control group $(50.4 \% \pm 2.4 \%$; $79.0 \% \pm 2.7 \%)(P<0.01)$. The PKA inhibitor $\mathrm{H}-89$ alone reduced the no-reflow size $(29.5 \% \pm 4.2 \%)$ relative to the control group $(P<0.01)$, but it partially abolished the SIM effect on no-reflow size and completely abolished the SIM effect on infarct size, indicated by the increased no-reflow $(40.4 \% \pm 6.1 \%)$ and infarct $(77.4 \% \pm 1.2 \%)$ sizes, respectively, in the SIM+H-89 group. However, the eNOS inhibitor L-NNA completely counteracted the effects of SIM on myocardial no-reflow and infarction; the no-reflow and infarction sizes in the SIM+L-NNA group reverted to the control levels $(52.3 \% \pm 2.8 \% ; 83.9 \% \pm 2.5 \%)$ $(P<0.01)$. These data indicate that the cardioprotective effects of SIM against no-reflow and infarction are completely eNOSdependent but partially PKA-dependent.

After $1.5 \mathrm{~h}$ of ischemia and $3 \mathrm{~h}$ of reperfusion, plasma CK activity, a standard enzymatic marker of cardiac injury, was significantly increased in the control group $(2.97 \pm 0.45 \mathrm{IU} /$ $\mathrm{mL} ; 4.73 \pm 0.14 \mathrm{IU} / \mathrm{mL})$ compared to the sham group $(1.05 \pm 0.09$ $\mathrm{IU} / \mathrm{mL} ; 1.59 \pm 0.25 \mathrm{IU} / \mathrm{mL})(P<0.01)$ but was lowered in the SIM group $(1.66 \pm 0.13 \mathrm{IU} / \mathrm{mL} ; 3.53 \pm 0.29 \mathrm{IU} / \mathrm{mL})$ compared to the control group $(P<0.01)$. However, the addition of $\mathrm{H}-89$ inhibited the SIM effect after $3 \mathrm{~h}$ of reperfusion, and L-NNA inhibited the SIM effect after $1.5 \mathrm{~h}$ of ischemia and $3 \mathrm{~h}$ of reperfusion (Figure 1C).

\section{Myocardial PKA activity in the reflow and no-reflow areas after ischemia and reperfusion}

Figure 2A shows that the PKA activity was dramatically induced in the reflow and no-reflow areas in the control group $(9.57 \pm 0.56 \mathrm{IU} / \mathrm{mL} ; 12.18 \pm 0.88 \mathrm{IU} / \mathrm{mL})$ compared with that in the sham group $(6.04 \pm 0.62 \mathrm{IU} / \mathrm{mL})(P<0.01)$. Myocardial PKA activity in the reflow and no-reflow areas were further activated in the SIM group $(12.24 \pm 0.76 \mathrm{IU} / \mathrm{mL} ; 14.47 \pm 0.44 \mathrm{IU} /$ $\mathrm{mL})$ compared to that in the control group $(P<0.05)$. However, SIM-induced PKA activity was inhibited by $\mathrm{H}-89$ but not by L-NNA.

To evaluate the inhibition effect of H-89 on the PKA signaling pathway, Western blotting analysis was performed to 
Table 1. Hemodynamic data at baseline, at the end of ischemia, and after reperfusion. Mean \pm SEM. $n=7-8$ animals/group. ${ }^{b} P<0.05$ vs Sham. ${ }^{\mathrm{e}} P<0.05$ vs Control. ${ }^{\mathrm{h}} P<0.05$ vs SIM at the same time point.

\begin{tabular}{|c|c|c|c|c|c|c|}
\hline & $\begin{array}{c}\text { HR } \\
\text { (beats/min) }\end{array}$ & $\begin{array}{c}\text { MAP } \\
(\mathrm{mmHg})\end{array}$ & $\begin{array}{c}\text { RPP } \\
\text { (mmHg.beats/min) }\end{array}$ & $\begin{array}{l}\text { LVEDP } \\
(\mathrm{mmHg})\end{array}$ & $\begin{array}{l}\mathrm{dp} / \mathrm{d} t_{\max } \\
(\mathrm{mmHg} / \mathrm{s})\end{array}$ & $\begin{array}{c}\mathrm{dp} / \mathrm{d} t_{\min } \\
(\mathrm{mmHg} / \mathrm{s})\end{array}$ \\
\hline \multicolumn{7}{|l|}{ Baseline } \\
\hline Sham group & $95.4 \pm 4.4$ & $87.8 \pm 7.5$ & $8411.8 \pm 900.6$ & $3.2 \pm 0.7$ & $1689.8 \pm 220.1$ & $-1309.7 \pm 225.5$ \\
\hline Control group & $102.6 \pm 10.3$ & $84.6 \pm 10.2$ & $8308.7 \pm 1023.1$ & $4.6 \pm 1.1$ & $1966.2 \pm 168$ & $-1574.1 \pm 121.8$ \\
\hline SIM group & $101.9 \pm 8.4$ & $93.5 \pm 7.6$ & $9135.5 \pm 458.9$ & $4.9 \pm 1.1$ & $1857.1 \pm 183.4$ & $-1581.8 \pm 242.0$ \\
\hline $\mathrm{SIM}+\mathrm{H}-89$ group & $112.7 \pm 6.4$ & $89.6 \pm 4.5$ & $9973.1 \pm 475.9$ & $3.9 \pm 0.6$ & $2083.4 \pm 186.9$ & $-1434.1 \pm 123.9$ \\
\hline H-89 group & $112.9 \pm 6.9$ & $76.1 \pm 7.4$ & $8621.4 \pm 1028.7$ & $5.1 \pm 1.1$ & $1844.9 \pm 160.1$ & $-1309.4 \pm 192.7$ \\
\hline SIM+L-NNA group & $95.4 \pm 8$ & $99.1 \pm 8.5$ & $9371.7 \pm 1081.9$ & $6 \pm 0.3$ & $1569.3 \pm 192.5$ & $-1512.2 \pm 205.4$ \\
\hline L-NNA group & $93.5 \pm 5.5$ & $102.2 \pm 6.9$ & $9438.9 \pm 630.6$ & $5.4 \pm 0.5$ & $1928.8 \pm 157.2$ & $-1832.2 \pm 165.6$ \\
\hline \multicolumn{7}{|l|}{ Ischemia $90 \mathrm{~min}$} \\
\hline Sham group & $89.4 \pm 7.7$ & $74.7 \pm 5.2$ & $6619.0 \pm 726.2$ & $3.6 \pm 0.7$ & $1820.7 \pm 198.0$ & $-503.1 \pm 397.1$ \\
\hline Control group & $126.0 \pm 6.2^{b}$ & $66.1 \pm 7.9$ & $8544.7 \pm 1354.0$ & $11.3 \pm 3.5^{b}$ & $1549.4 \pm 137.7$ & $-876.7 \pm 108.2$ \\
\hline SIM group & $85.6 \pm 13.8^{\mathrm{e}}$ & $65.0 \pm 2.9$ & $6808.0 \pm 968.2$ & $6.7 \pm 1.5$ & $1737.8 \pm 129.0$ & $-1096.7 \pm 96.9$ \\
\hline $\mathrm{SIM}+\mathrm{H}-89$ group & $90.3 \pm 11.6$ & $61.5 \pm 3.2$ & $4220.0 \pm 301.5^{\mathrm{h}}$ & $9.8 \pm 2.8$ & $1164.4 \pm 99.8^{h}$ & $-713.9 \pm 107.1$ \\
\hline $\mathrm{H}-89$ group & $89.8 \pm 7.3^{\mathrm{e}}$ & $70.8 \pm 6.1$ & $6585.0 \pm 1003.5$ & $7.5 \pm 1.3$ & $1389.5 \pm 91.2$ & $-805.2 \pm 87.0$ \\
\hline SIM+L-NNA group & $100.3 \pm 3.2$ & $97.1 \pm 5.4^{\mathrm{h}}$ & $9754.1 \pm 666.8^{h}$ & $8.3 \pm 1.3$ & $1262.6 \pm 171.7^{\mathrm{h}}$ & $-880.4 \pm 193$ \\
\hline L-NNA group & $103.6 \pm 4.4$ & $98.4 \pm 7.3^{\mathrm{e}}$ & $9208.9 \pm 777.8$ & $10 \pm 1.7$ & $1733.1 \pm 89.5$ & $-844.9 \pm 74.1$ \\
\hline \multicolumn{7}{|c|}{ Reperfusion $180 \mathrm{~min}$} \\
\hline Sham group & $69.4 \pm 4.9$ & $75.4 \pm 4.3$ & $5215.7 \pm 462$ & $4.0 \pm 1.0$ & $1650.3 \pm 231.7$ & $-846.7 \pm 105.5$ \\
\hline Control group & $80.2 \pm 7.8$ & $67.0 \pm 9.0$ & $5354.3 \pm 966.4$ & $12.8 \pm 2.6^{\mathrm{b}}$ & $1236.2 \pm 139.6$ & $-691.9 \pm 70.5$ \\
\hline SIM group & $80.3 \pm 7.1$ & $76.0 \pm 4.6$ & $6131.6 \pm 774.2$ & $6.8 \pm 1.4^{\mathrm{e}}$ & $1718.7 \pm 250.0$ & $-949.1 \pm 112.7$ \\
\hline $\mathrm{SIM}+\mathrm{H}-89$ group & $95.8 \pm 11.9$ & $59.0 \pm 5.8^{h}$ & $5661.8 \pm 859.8$ & $7.7 \pm 1.6$ & $1397.7 \pm 183.6$ & $-786.7 \pm 70.1$ \\
\hline $\mathrm{H}-89$ group & $84.3 \pm 3.4$ & $70.4 \pm 3.8$ & $5963.3 \pm 442.9$ & $6.9 \pm 1.3^{\mathrm{e}}$ & $1385.2 \pm 245.3$ & $-790.3 \pm 192.6$ \\
\hline SIM+L-NNA group & $79.4 \pm 5.3$ & $79.3 \pm 6.4$ & $6338.2 \pm 660.8$ & $8.8 \pm 0.9$ & $1013.6 \pm 111.9^{h}$ & $-684.2 \pm 57.2$ \\
\hline L-NNA group & $85.8 \pm 5.7$ & $82.1 \pm 5.3$ & $6334 \pm 834.5$ & $6.2 \pm 1.2^{\mathrm{e}}$ & $1265.9 \pm 146.6$ & $-886.7 \pm 205.1$ \\
\hline
\end{tabular}

Abbreviations: $\mathrm{SIM}=$ simvastatin; $L-N N A=N^{\omega}$-nitro- $L$-arginine; $H R=$ heart rate; $M A P=$ mean arterial pressure; $R P P=$ rate-pressure product; $L V E D P=l$ eft ventricular end-diastolic pressure; $\mathrm{dp} / \mathrm{d} t_{\max }$ and $\mathrm{d} p / \mathrm{d} t_{\min }=$ maximum and minimum rates of left ventricular pressure development, respectively.

detect the expression of $\operatorname{Ser}^{133} \mathrm{p}$-CREB, which acts downstream of PKA and is thus an indicator of PKA activity ${ }^{[13]}$ (Figure 2B, $2 \mathrm{C}$, and $2 \mathrm{D}$ ). In the non-ischemic area (Figure 2B), the expression of $\mathrm{Ser}^{133} \mathrm{p}$-CREB was reduced in the SIM and $\mathrm{H}-89$ groups compared to the control group $(P<0.05)$. In the reflow and no-reflow myocardium (Figure $2 \mathrm{C}$ and $2 \mathrm{D}$ ), $\operatorname{Ser}^{133} \mathrm{p}$-CREB was up-regulated in the control group compared to the sham group $(P<0.05)$ and was further activated in the SIM group compared to the control group $(P<0.05)$. The induction effect of SIM on Ser ${ }^{133}$ p-CREB expression was abolished by H-89 but not by $L$-NNA $(P<0.05)$. These data suggest that the PKA pathway was activated during ischemia and reperfusion and was further stimulated by SIM pretreatment.

\section{Myocardial NOS activities in the reflow and no-reflow areas after ischemia and reperfusion}

In the non-ischemic area (Figure $3 \mathrm{~A})$, cNOS activity was increased in the control group $(0.68 \pm 0.15 \mathrm{IU} / \mathrm{mg}$ prot $)$ relative to the sham group $(0.26 \pm 0.08 \mathrm{IU} / \mathrm{mg}$ prot $)(P<0.01)$. In the reflow and no-reflow areas (Figure $3 \mathrm{~B}$ and $3 \mathrm{C}$ ), tNOS activity was decreased in the SIM+H-89 $(0.63 \pm 0.09 \mathrm{IU} / \mathrm{mg}$ prot; $0.59 \pm 0.05 \mathrm{IU} / \mathrm{mg}$ prot) and SIM+L-NNA $(0.73 \pm 0.06$
$\mathrm{IU} / \mathrm{mg}$ prot; $0.73 \pm 0.05 \mathrm{IU} / \mathrm{mg}$ prot) groups relative to the SIM group $(0.97 \pm 0.13 \mathrm{IU} / \mathrm{mg}$ prot; $0.94 \pm 0.06 \mathrm{IU} / \mathrm{mg}$ prot $)$ $(P<0.05)$; iNOS activity was decreased in the control group $(0.37 \pm 0.08 \mathrm{IU} / \mathrm{mg}$ prot; $0.32 \pm 0.09 \mathrm{IU} / \mathrm{mg}$ prot$)$ relative to the sham group $(0.76 \pm 0.11 \mathrm{IU} / \mathrm{mg}$ prot $)(P<0.01)$; and cNOS activity was increased in the SIM group $(0.67 \pm 0.15 \mathrm{IU} / \mathrm{mg}$ prot; $0.6 \pm 0.08 \mathrm{IU} / \mathrm{mg}$ prot$)$ relative to the control group $(0.4 \pm 0.11$ $\mathrm{IU} / \mathrm{mg}$ prot; $0.41 \pm 0.08 \mathrm{IU} / \mathrm{mg}$ prot $)(P<0.05)$ but decreased in the SIM+H-89 $(0.3 \pm 0.08 \mathrm{IU} / \mathrm{mg}$ prot; $0.31 \pm 0.07 \mathrm{IU} / \mathrm{mg}$ prot $)$ and SIM+L-NNA $(0.28 \pm 0.07 \mathrm{IU} / \mathrm{mg}$ prot; $0.2 \pm 0.04 \mathrm{IU} / \mathrm{mg}$ prot $)$ groups compared to the SIM group $(P<0.01)$.

To investigate the mechanism by which PKA mediates eNOS activity, the expression of eNOS and p-eNOS (Ser ${ }^{1179}$ and $\operatorname{Ser}^{635}$ ) was detected by Western blotting analysis (Figure $2 \mathrm{~B}, 2 \mathrm{C}$, and 2D). In the non-ischemic area (Figure 2B), the expression of eNOS and $\operatorname{Ser}^{635}$ p-eNOS was increased in the control group compared to that in the sham group $(P<0.05)$; the eNOS expression in the SIM and SIM $+\mathrm{H}-89$ groups was decreased, and the Ser ${ }^{635}$ p-eNOS expression in the H-89 group was increased, compared to that of the control group $(P<0.05)$. In the reflow area (Figure $2 \mathrm{C}$ ), the expression of eNOS and Ser $^{635}$ p-eNOS was increased in the control group 
A

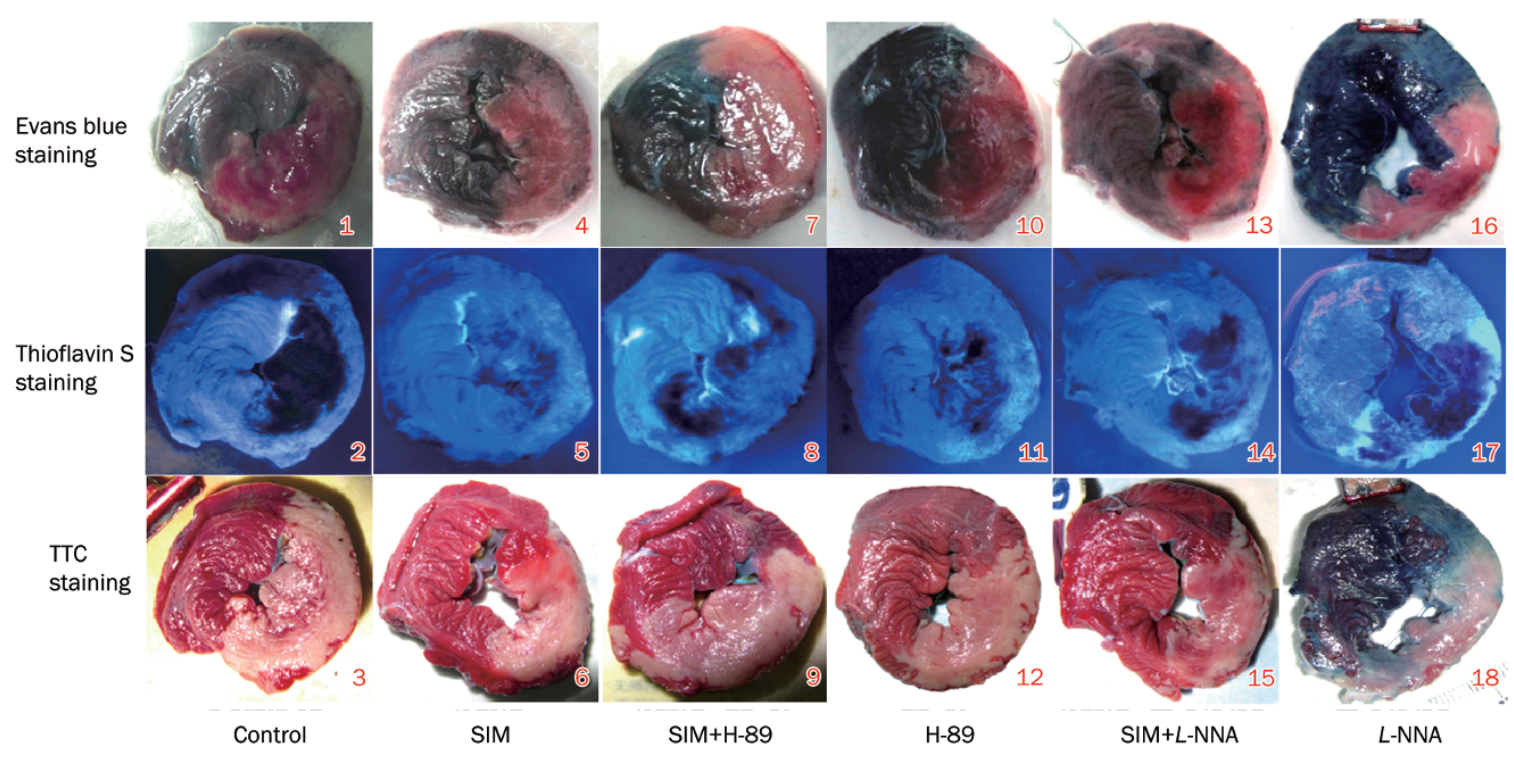

B

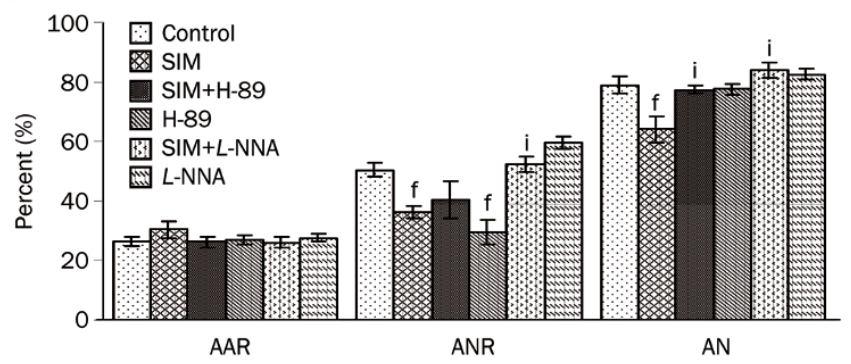

C

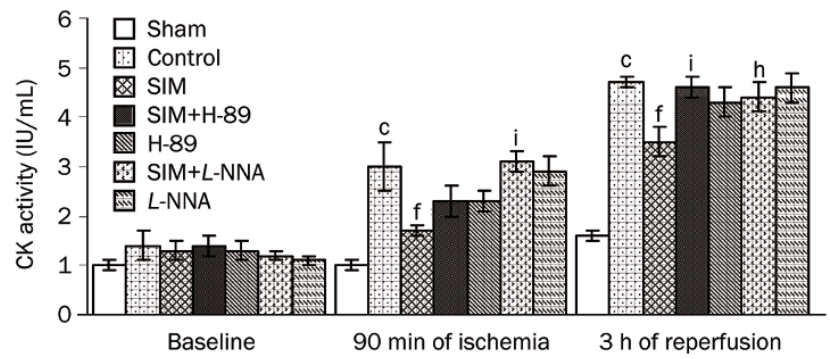

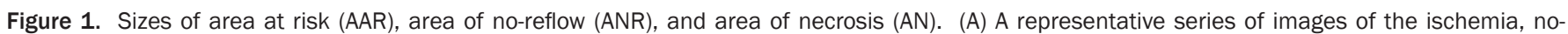

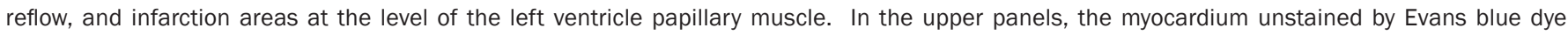

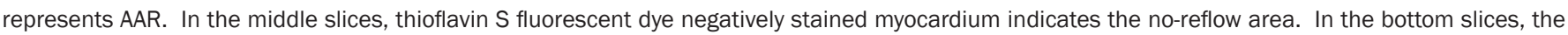

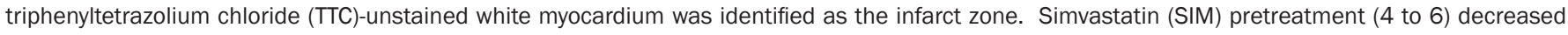

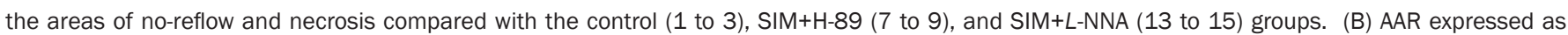

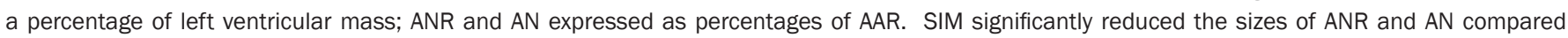

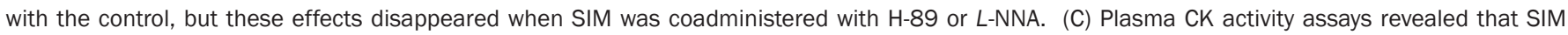

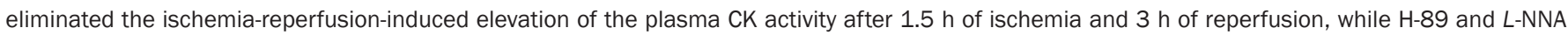

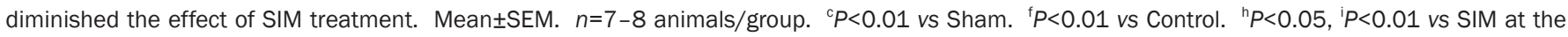
same time point.

compared with that in the sham group $(P<0.05)$; the Ser ${ }^{1179}$ p-eNOS and Ser ${ }^{635}$ p-eNOS phosphorylation was increased in the SIM group compared to that in the control group $(P<0.05)$; $\mathrm{H}-89$ suppressed the induction effect of SIM on $\operatorname{Ser}^{635} \mathrm{p}$-eNOS $(P<0.05)$, and L-NNA suppressed the induction effect of SIM on both $\operatorname{Ser}^{1179}$ p-eNOS and $\operatorname{Ser}^{635}$ p-eNOS $(P<0.05)$. In the noreflow area (Figure 2D), Ser ${ }^{1179}$ p-eNOS phosphorylation was higher in the control group than in the sham group $(P<0.05)$. The level of Ser $^{635}$ p-eNOS was increased in the SIM and $\mathrm{H}-89$ groups compared to that of the control group $(P<0.05)$, whereas the levels of Ser ${ }^{1179}$ p-eNOS and $\operatorname{Ser}^{635}$ p-eNOS were decreased in the SIM+L-NNA group $(P<0.05)$.

\section{Discussion}

The main findings of our study include the following: first, a single-dose SIM pretreatment just 2.5 hours before reperfusion reduced the sizes of the no-reflow and necrosis areas and activated the PKA pathway and the phosphorylation of eNOS at $\operatorname{Ser}^{635}$ and Ser ${ }^{1179}$ in the reflow and no-reflow myocardium. Second, the PKA inhibitor H-89 blocked the SIM-induced PKA activation and partially abolished the SIM-induced cardioprotection and eNOS phosphorylation, whereas the eNOS inhibitor L-NNA completely blocked the SIM-induced cardioprotection and eNOS phosphorylation without any influence on PKA activity, indicating that the cardioprotection of SIM after ischemia and reperfusion is in part mediated by the PKA/ eNOS pathway.

Previous studies have reported that a 3-day pretreatment with atorvastatin or SIM at $10 \mathrm{mg} / \mathrm{kg}$ per day decreased the infarct size in rat hearts, but this effect was not observed at 
C

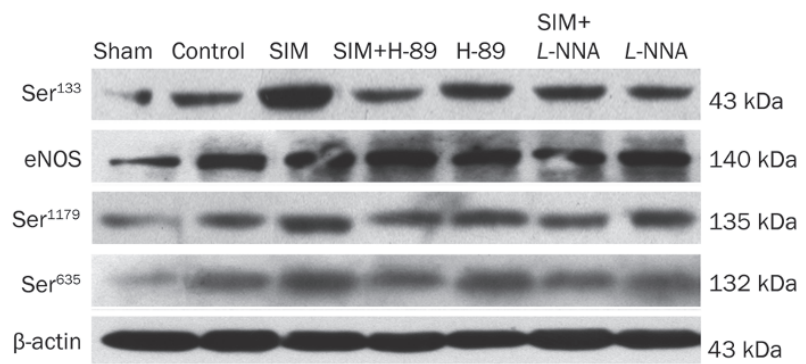

A
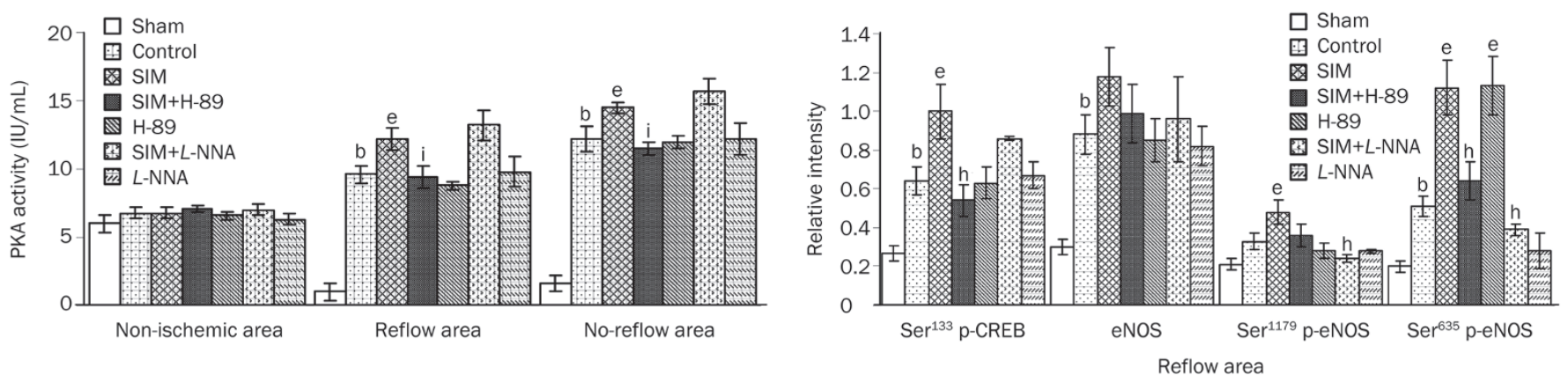

B

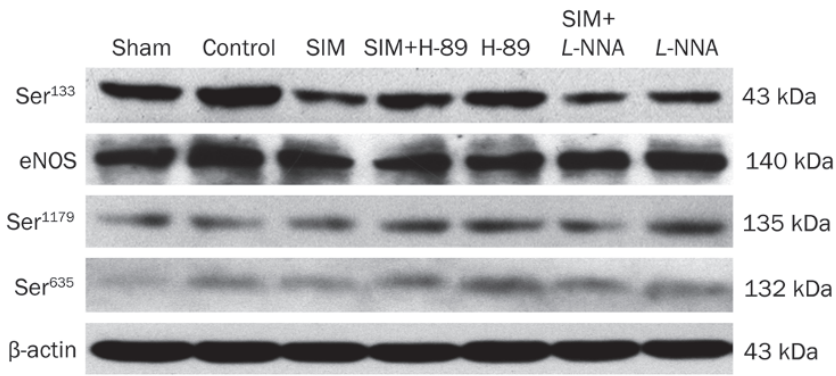

D
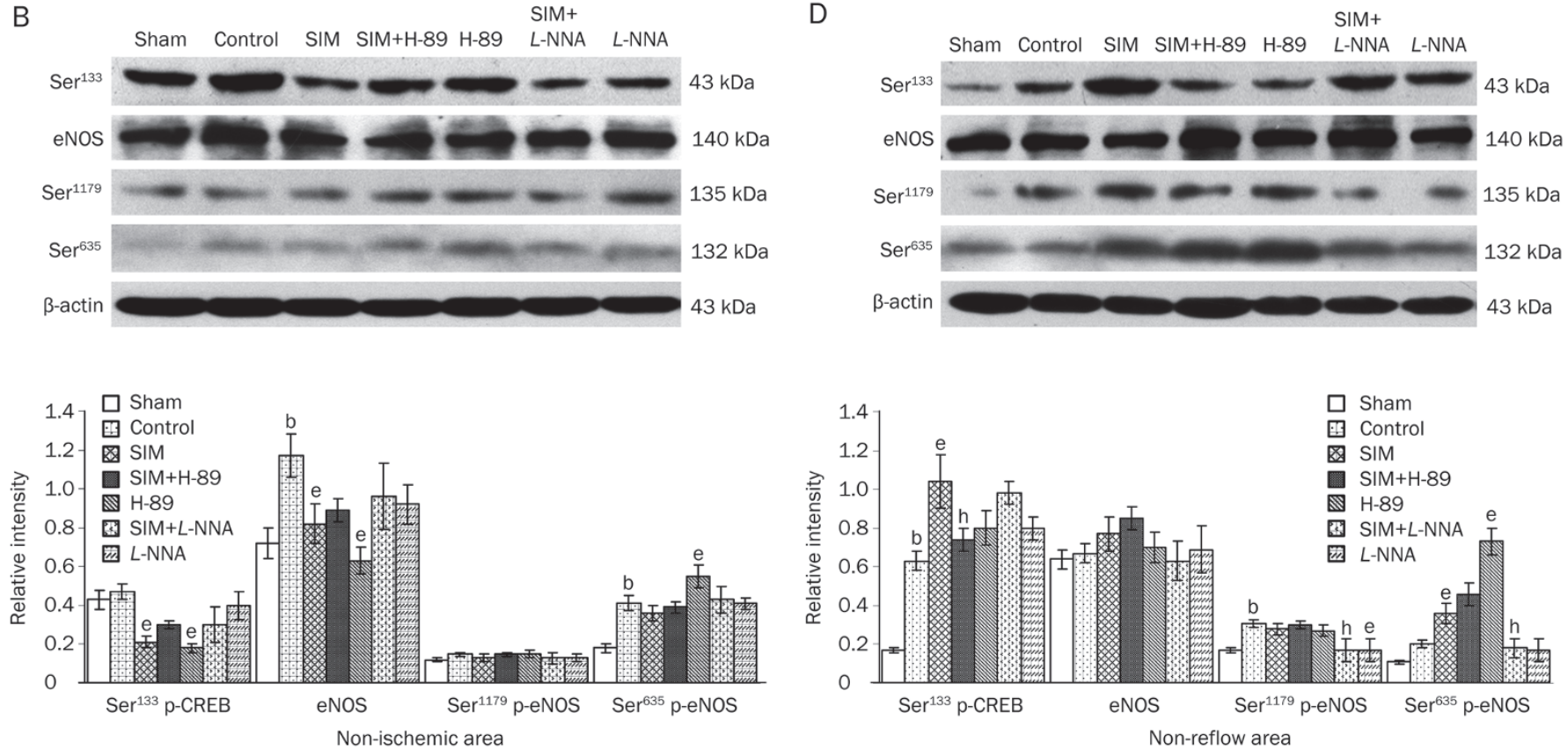

Figure 2. Myocardial PKA activity and the expression of Ser ${ }^{133}$ p-CREB, eNOS and p-eNOS (Ser ${ }^{1179}$ and Ser ${ }^{635}$ ) after ischemia and reperfusion. (A) Myocardial PKA activities in the reflow and no-reflow areas were stimulated by ischemia and reperfusion and were further increased by SIM pretreatment. However, the SIM-induced activation of PKA was silenced by $\mathrm{H}-89$ but not by L-NNA. (B) In the non-ischemic area, the expression of eNOS and Ser ${ }^{635}$ p-eNOS was increased in the control group, and the expression of Ser ${ }^{133}$ p-CREB and eNOS was decreased in the SIM and H-89 groups. (C) In the reflow area, the expression of $\mathrm{Ser}^{133} \mathrm{p}$-CREB, eNOS, and $\mathrm{Ser}^{635} \mathrm{p}$-eNOS was stimulated by ischemia and reperfusion. SIM promoted the phosphorylation of Ser ${ }^{133}$ p-CREB, Ser ${ }^{1179}$ p-eNOS, and Ser $r^{635}$ p-eNOS. However, H-89 counteracted the effects of SIM on Ser ${ }^{133}$ p-CREB and Ser ${ }^{635}$ p-eNOS, and L-NNA canceled the effects of SIM on Ser ${ }^{1179}$ p-eNOS and Ser ${ }^{635}$ p-eNOS. (D) In the no-reflow area, ischemia and reperfusion induced the phosphorylation of $\operatorname{Ser}^{133}$ p-CREB and Ser ${ }^{1179}$ p-eNOS. SIM pretreatment increased the phosphorylation of Ser ${ }^{133}$ p-CREB and Ser ${ }^{635}$ p-eNOS. H-89 blocked the effect of SIM on Ser ${ }^{133} p$-CREB, and L-NNA inhibited the SIM effects on Ser ${ }^{1179}$ p-eNOS and Ser ${ }^{635} p$-eNOS. Mean $\pm S E M$. $n=7-8$ animals/ group. ${ }^{\mathrm{b}} P<0.05$ vs Sham. ${ }^{\mathrm{e}} \mathrm{P}<0.05$ vs Control. ${ }^{\mathrm{h}} \mathrm{P}<0.05$, ${ }^{\mathrm{i}} \mathrm{P}<0.01$ vs $\mathrm{SIM}$ at the same time point.

$2 \mathrm{mg} / \mathrm{kg}^{[4,6,20,21]}$. Similarly, acute pretreatment with highdose SIM $(10 \mu \mathrm{mol} / \mathrm{L})$ was shown to attenuate the ischemia- reperfusion injury in isolated rat hearts, but chronic treatment of low-dose SIM did not ${ }^{[2]}$. These data suggest that chronic 

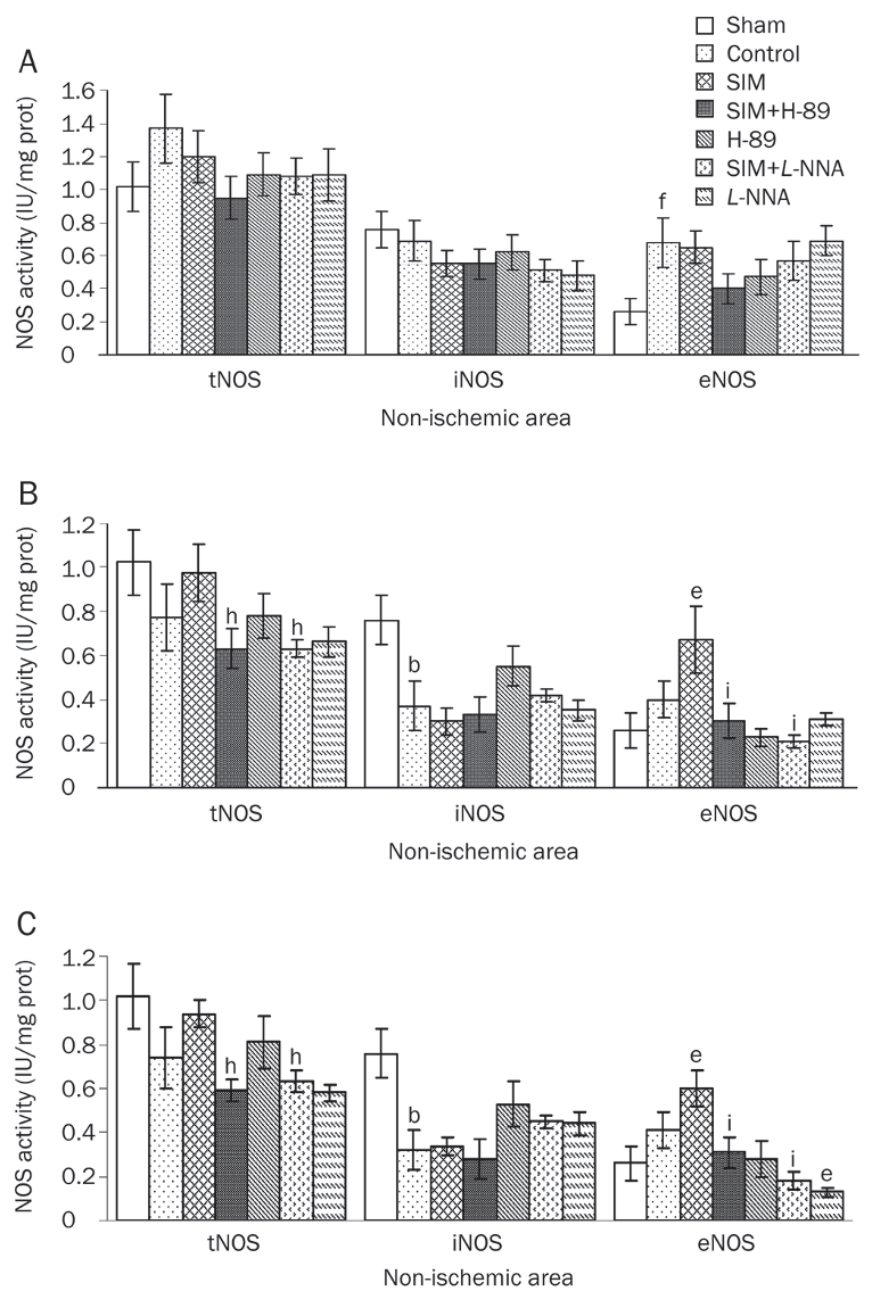

Figure 3. Myocardial NOS activity in the injured and uninjured myocardium after ischemia and reperfusion. (A) After ischemia and reperfusion, myocardial constitutive (cNOS) activities were increased in the nonischemic area in the control group. ( $\mathrm{B}$ and $\mathrm{C}$ ) In the reflow and no-reflow myocardium, inducible (iNOS) activity was suppressed in the control group. SIM pretreatment significantly stimulated cNOS activity, but this effect was abolished by cotreatment with $\mathrm{H}-89$ or L-NNA. Abbreviation: tNOS=total nitric oxide synthase. Mean \pm SEM. $n=7-8$ animals/group. ${ }^{\mathrm{b}} P<0.05$ vs Sham. ${ }^{\mathrm{e}} P<0.05,{ }^{\mathrm{f}} P<0.01$ vs Control. ${ }^{\mathrm{h}} P<0.05,{ }^{\mathrm{i}} P<0.01$ vs SIM at the same time point.

or acute pretreatment with high-dose statins can attenuate infarct size after ischemic reperfusion. The effect of SIM on infarct size in this study is consistent with that found in previous studies because $2 \mathrm{mg} / \mathrm{kg}$ of SIM in pigs is approximately equivalent to $10 \mathrm{mg} / \mathrm{kg}$ in rats, after correction for body surface area ${ }^{[15]}$. The infarct-limitation effect of statins in ischemiareperfusion is mainly attributed to its pleiotropic effects via the PI3K/Akt/eNOS pathway because the effects of the statins can be abolished by inhibiting PI3K or eNOS ${ }^{[5-9]}$. In this study, we further found that acute pretreatment with single-dose SIM not only decreased the infarct size but also attenuated the no-reflow area, and we showed that the PKA pathway was another important mediator in the cardioprotection of SIM that acts by modulating the phosphorylation of eNOS at Ser ${ }^{1179}$ and Ser ${ }^{635}$.

PKA seems to be activated by endogenous mechanisms because the PKA inhibitor H89 alone had almost the same effect as SIM on the no-reflow area in the presence of ischemia. The mechanism underlying the idiopathetic activation of PKA is considered to be that the decreased level of cyclic guanosine monophosphate (cGMP) inhibits the activity of phosphodiesterase III upon reperfusion, which in turn increases the cAMP concentration, subsequently leading to PKA activation $^{[23]}$. The inhibition of PKA activity and $\operatorname{Ser}^{133}$ p-CREB by H-89 indicates that acute SIM treatment actually results in PKA activation. Although it is presently unclear how statins activate PKA in ischemic myocardium, one probable explanation is that statins may stimulate a cell surface receptor that activates small $G$ proteins, which results in the sensitization of adenylate cyclase and the accumulation of myocardial cAMP $^{[24]}$ and eventually the activation of PKA in the ischemic myocardium. It has been reported that $5^{\prime}$-nucleotidase and the adenosine $\mathrm{A} 1, \mathrm{~A} 2 \mathrm{~A}$, and $\mathrm{A} 2 \mathrm{~B}$ receptors are involved in atorvastatin-induced eNOS phosphorylation by stimulating phospholipase $\mathrm{A}_{2}$ and cyclooxygenase (COX) to generate prostacyclin-2 $\left(\mathrm{PGI}_{2}\right)$, leading to PKA activation and subsequent eNOS phosphorylation ${ }^{[5,25]}$.

Enhancing Ser ${ }^{1177 / 1179}$ phosphorylation via the PI3K/Akt pathway is considered to be the main mechanism by which statins protect against ischemia-reperfusion injury ${ }^{[5-9]}$. However, several lines of evidence have shown that PKA also regulates the phosphorylation of eNOS at Ser ${ }^{1179}, \operatorname{Ser}^{635}$, and $\operatorname{Ser}^{617}$ in bovine eNOS (Ser ${ }^{1177}$, Ser ${ }^{633}$, and Ser ${ }^{615}$ in humans) ${ }^{[24,26-29]}$. $\mathrm{Ser}^{633 / 635}$ phosphorylation is critical in maintaining NO synthesis after the initial sensitization by $\mathrm{Ca}^{2+}$ flux and Ser ${ }^{177 / 1179}$ phosphorylation ${ }^{[30]}$, and it is stimulated via the PKA pathway in response to shear stress and acute statin treatment in aortic endothelial cells ${ }^{[24,27]}$, suggesting that PKA-mediated $\operatorname{Ser}^{633 / 635}$ phosphorylation may be another mechanism by which statins protect against myocardial no-reflow and necrosis after ischemia and reperfusion. Our study confirmed this hypothesis in reperfused swine hearts, demonstrating that the inhibition of PKA partially blocked the SIM-induced phosphorylation of eNOS at Ser ${ }^{1179}$ and Ser ${ }^{635}$ in the reflow and no-reflow myocardium, as well as partially abrogated the effects of SIM against myocardial no-reflow and infarction. Previous studies have reported that statin-induced eNOS activation involves the inhibition of the Rho GTPase and the modulation of Rho A membrane translocation ${ }^{[31,32]}$ and that the transient preischemic activation of PKA by ischemic preconditioning reduces infarct size through Rho and Rho-kinase (ROCK) inhibition during sustained ischemia ${ }^{[13]}$. Therefore, it is plausible that PKA-Rho pathway is involved in the regulation of eNOS activity by statins, but the specific mechanism should be studied further.

Here, H-89 administered $30 \mathrm{~min}$ before ischemia attenuated the no-reflow area, possibly by phosphorylating eNOS at $\mathrm{Ser}^{635}$, but partly inhibited the protective effects of SIM when infused $30 \mathrm{~min}$ after SIM administration. This finding 
is somewhat contradictory to previous studies. In isolated rat hearts, H-89 $(2 \mu \mathrm{mol} / \mathrm{L})$ improved postischemic function and decreased infarct size when injected $3 \mathrm{~min}$ before $30 \mathrm{~min}$ of global ischemia-reperfusion and further reduced the infarct size when administered $3 \mathrm{~min}$ prior to ischemic or forskolin (a cAMP-elevating agents) preconditioning ${ }^{[33]}$. However, when delivered at $1.35 \mu \mathrm{g} / \mathrm{kg}$ per minute in dogs or at $10 \mu \mathrm{mol} / \mathrm{L}$ in isolated rat hearts approximately $30 \mathrm{~min}$ before preconditioning, H-89 completely blunted the infarct-limitation effect of preconditioning ${ }^{[12,34]}$. Therefore, the partial inhibition of H-89 on SIM cardioprotection in our study most likely occurred because $\mathrm{H}-89$ was delivered later than SIM, and the contradiction between these studies might be explained by the differences in H-89 dosage, experimental protocols, and animal species.

Another mechanism underlying the bidirectional role of H-89 in ischemia and reperfusion may be the cross-talk between the PKA and PI3K/Akt pathways in the regulation of eNOS phosphorylation. It has been reported that H-89 inhibits Akt, ROCK II, and $5^{\prime}$-AMP-activated protein kinase (AMPK) $)^{[35]}$ and that the PKA pathway interacts with the PI3K/Akt pathway in the regulation of gene expression ${ }^{[36]}$. Previous studies have shown that the forskolin-induced stimulation of PKA can inhibit Akt activity in human embryonic kidney cells ${ }^{[37]}$, but epinephrine or forskolin-induced stimulation of PKA enhanced eNOS phosphorylation at Ser ${ }^{1177}$ by activating the Akt pathway in aortic or coronary endothelial cells ${ }^{[28,38]}$. Interestingly, in endothelial cells, PKA is mainly involved in eNOS phosphorylation during the early phase of preconditioning, whereas both PKA and Akt are required for late preconditioning-induced eNOS activation, and Akt is a substrate of PKA ${ }^{[39]}$. Therefore, these reports indicate that PKA plays different roles in regulating eNOS phosphorylation in different cells and that cross-talk most likely exists between the PKA and PI3K/Akt pathways in the regulation of eNOS phosphorylation during ischemia and reperfusion. The inhibition of PKA may in turn cause the activation of the PI3K/Akt pathway and the subsequent phosphorylation of $\operatorname{Ser}^{635}$ p-eNOS. This might be another explanation of why H-89 partially inhibited SIMinduced cardioprotection in our study; the exact mechanism may be elucidated in the future when more selective PKA inhibitors are available.

In summary, the present study suggests that acute pretreatment with a single dose of SIM just $2.5 \mathrm{~h}$ before reperfusion can attenuate the size of the no-reflow and infarction areas by phosphorylating eNOS at $\operatorname{Ser}^{1179}$ and $\operatorname{Ser}^{635}$ in a partially PKA-dependent manner. The observation that $\mathrm{H}-89$ partially abolished the cardioprotective effects of SIM and decreased the no-reflow size when administered alone suggests a bidirectional role for PKA in cardioprotection during ischemia and reperfusion. Our results are helpful for understanding the mechanisms involved in statin-mediated protection against myocardial no-reflow and infarction, and may lead to the development of new criteria for treating patients undergoing acute post-infarct percutaneous coronary intervention.

\section{Acknowledgements}

This study was supported by the National Basic Research Program (973 Program) of China (No 2012 CB518602 and 2011CB503901).

\section{Author contribution}

Yue-jin YANG, Xiang-dong LI, and Yi-ling WU designed research; Xiang-dong LI, Jing-lin ZHAO, Hai-tao ZHANG, and Yu-tong CHENG performed research and analyzed data; Xiang-dong LI and Yong-jian GENG wrote the paper.

\section{References}

1 Ito H, Maruyama A, Iwakura K, Takiuchi S, Masuyama T, Hori M, et al. Clinical implications of the 'no reflow' phenomenon. A predictor of complications and left ventricular remodeling in reperfused anterior wall myocardial infarction. Circulation 1996; 93: 223-8.

2 Stone GW, Peterson MA, Lansky AJ, Dangas G, Mehran R, Leon MB. Impact of normalized myocardial perfusion after successful angioplasty in acute myocardial infarction. J Am Coll Cardiol 2002; 39: 591-7.

3 Resnic FS, Wainstein M, Lee MK, Behrendt D, Wainstein RV, OhnoMachado L, et al. No-reflow is an independent predictor of death and myocardial infarction after percutaneous coronary intervention. Am Heart J 2003; 145: 42-46.

4 Zhao JL, Yang YJ, Cui CJ, You SJ, Gao RL. Pretreatment with simvastatin reduces myocardial no-reflow by opening mitochondrial K(ATP) channel. Br J Pharmacol 2006; 149: 243-9.

5 Merla R, Ye Y, Lin Y, Manickavasagam S, Huang MH, Perez-Polo RJ, et al. The central role of adenosine in statin-induced ERK1/2, Akt, and eNOS phosphorylation. Am J Physiol Heart Circ Physiol 2007; 293: H1918-28.

6 Manickavasagam S, Ye Y, Lin Y, Perez-Polo RJ, Huang MH, Lui CY, et al. The cardioprotective effect of a statin and cilostazol combination: relationship to Akt and endothelial nitric oxide synthase activation. Cardiovasc Drugs Ther 2007; 21: 321-30.

7 Iwakura K, Ito H, Kawano S, Okamura A, Kurotobi T, Date M, et al. Chronic pre-treatment of statins is associated with the reduction of the no-reflow phenomenon in the patients with reperfused acute myocardial infarction. Eur Heart J 2006; 27: 534-9.

8 Efthymiou CA, Mocanu MM, Yellon DM. Atorvastatin and myocardial reperfusion injury: new pleiotropic effect implicating multiple prosurvival signaling. J Cardiovasc Pharmacol 2005; 45: 247-52.

9 Birnbaum Y, Ye Y, Rosanio S, Tavackoli S, Hu ZY, Schwarz ER, et al. Prostaglandins mediate the cardioprotective effects of atorvastatin against ischemia-reperfusion injury. Cardiovasc Res 2005; 65: 345 55.

10 Heusch G, Kleinbongard P, Bose D, Levkau B, Haude M, Schulz R, et al. Coronary microembolization: from bedside to bench and back to bedside. Circulation 2009; 120: 1822-36.

11 Van de Werf F, Bax J, Betriu A, Blomstrom-Lundqvist C, Crea F, Falk $V$, et al. Management of acute myocardial infarction in patients presenting with persistent ST-segment elevation: the Task Force on the Management of ST-Segment Elevation Acute Myocardial Infarction of the European Society of Cardiology. Eur Heart J 2008; 29: 290945.

12 Inserte J, Garcia-Dorado D, Ruiz-Meana M, Agullo L, Pina P, Soler-Soler J. Ischemic preconditioning attenuates calpain-mediated degradation of structural proteins through a protein kinase A-dependent mechanism. Cardiovasc Res 2004; 64: 105-14. 
13 Sanada S, Asanuma H, Tsukamoto O, Minamino T, Node K, Takashima S, et al. Protein kinase $\mathrm{A}$ as another mediator of ischemic preconditioning independent of protein kinase C. Circulation 2004; 110: $51-7$.

14 Li XD, Yang YJ, Geng YJ, Jin C, Hu FH, Zhao JL, et al. Tongxinluo reduces myocardial no-reflow and ischemia-reperfusion injury by stimulating the phosphorylation of eNOS via the PKA pathway. Am J Physiol Heart Circ Physiol 2010; 299: H1255-61.

15 Freireich EJ, Gehan EA, Rall DP, Schmidt LH, Skipper HE. Quantitative comparison of toxicity of anticancer agents in mouse, rat, hamster, dog, monkey, and man. Cancer Chemother Rep 1966; 50: 219-44.

16 Cheng YT, Yang YJ, Zhang HT, Qian HY, Zhao JL, Meng XM, et al. Pretreatment with Tongxinluo protects porcine myocardium from ischaemia/reperfusion injury through a nitric oxide related mechanism. Chin Med J(Engl) 2009; 122: 1529-38.

17 Brahmajothi MV, Campbell DL. Heterogeneous basal expression of nitric oxide synthase and superoxide dismutase isoforms in mammalian heart: implications for mechanisms governing indirect and direct nitric oxide-related effects. Circ Res 1999; 85: 575-87.

18 Wu ZQ, Li M, Chen J, Chi ZQ, Liu JG. Involvement of CAMP/CAMPdependent protein kinase signaling pathway in regulation of $\mathrm{Na}^{+}, \mathrm{K}^{+}-$ ATPase upon activation of opioid receptors by morphine. Mol Pharmacol 2006; 69: 866-76.

19 Robinet A, Hoizey G, Millart H. PI3-kinase, protein kinase C, and protein kinase $\mathrm{A}$ are involved in the trigger phase of beta1-adrenergic preconditioning. Cardiovasc Res 2005; 66: 530-42.

20 Ye Y, Lin Y, Perez-Polo R, Huang MH, Hughes MG, McAdoo DJ, et al. Enhanced cardioprotection against ischemia-reperfusion injury with a dipyridamole and low-dose atorvastatin combination. Am J Physiol Heart Circ Physiol 2007; 293: H813-8.

21 Birnbaum Y, Lin Y, Ye Y, Merla R, Perez-Polo JR, Uretsky BF. Pretreatment with high-dose statin, but not low-dose statin, ezetimibe, or the combination of low-dose statin and ezetimibe, limits infarct size in the rat. J Cardiovasc Pharmacol Ther 2008; 13: 72-9.

22 Szarszoi O, Maly J, Ostadal P, Netuka I, Besik J, Kolar F, et al. Effect of acute and chronic simvastatin treatment on post-ischemic contractile dysfunction in isolated rat heart. Physiol Res 2008; 57: 793-6.

23 Schulz R, Kelm M, Heusch G. Nitric oxide in myocardial ischemia/ reperfusion injury. Cardiovasc Res 2004; 61: 402-13.

24 Harris MB, Blackstone MA, Sood SG, Li C, Goolsby JM, Venema VJ, et al. Acute activation and phosphorylation of endothelial nitric oxide synthase by HMG-CoA reductase inhibitors. Am J Physiol Heart Circ Physiol 2004; 287: H560-6.

25 Ray CJ, Marshall JM. The cellular mechanisms by which adenosine evokes release of nitric oxide from rat aortic endothelium. J Physiol 2006; 570: 85-96.

26 Boo YC, Sorescu G, Boyd N, Shiojima I, Walsh K, Du J, et al. Shear stress stimulates phosphorylation of endothelial nitric-oxide synthase at Ser1179 by Akt-independent mechanisms: role of protein kinase A.
J Biol Chem 2002; 277: 3388-96.

27 Boo YC, Hwang J, Sykes M, Michell BJ, Kemp BE, Lum H, Jo H. Shear stress stimulates phosphorylation of eNOS at Ser(635) by a protein kinase A-dependent mechanism. Am J Physiol Heart Circ Physiol 2002; 283: H1819-28.

28 Zhang XP, Hintze TH. cAMP signal transduction induces eNOS activation by promoting PKB phosphorylation. Am J Physiol Heart Circ Physiol 2006; 290: H2376-84.

29 Michell BJ, Harris MB, Chen ZP, Ju H, Venema VJ, Blackstone MA, et al. Identification of regulatory sites of phosphorylation of the bovine endothelial nitric-oxide synthase at serine 617 and serine 635 . J Biol Chem 2002; 277: 42344-51.

30 Mount PF, Kemp BE, Power DA. Regulation of endothelial and myocardial NO synthesis by multi-site eNOS phosphorylation. J Mol Cell Cardiol 2007; 42: 271-9.

31 Rikitake Y, Liao JK. Rho GTPases, statins, and nitric oxide. Circ Res 2005; 97: 1232-5.

32 Bulhak A, Roy J, Hedin U, Sjoquist PO, Pernow J. Cardioprotective effect of rosuvastatin in vivo is dependent on inhibition of geranylgeranyl pyrophosphate and altered RhoA membrane translocation. Am J Physiol Heart Circ Physiol 2007; 292: H3158-63.

33 Makaula S, Lochner A, Genade S, Sack MN, Awan MM, Opie LH. H-89, a non-specific inhibitor of protein kinase $A$, promotes post-ischemic cardiac contractile recovery and reduces infarct size. J Cardiovasc Pharmacol 2005; 45: 341-7.

34 Sanada S, Kitakaze M, Papst PJ, Asanuma H, Node K, Takashima $\mathrm{S}$, et al. Cardioprotective effect afforded by transient exposure to phosphodiesterase III inhibitors: the role of protein kinase A and p38 mitogen-activated protein kinase. Circulation 2001; 104: 705-10.

35 Davies SP, Reddy H, Caivano M, Cohen P. Specificity and mechanism of action of some commonly used protein kinase inhibitors. Biochem J 2000; 351: 95-105.

36 Soria LR, Gradilone SA, Larocca MC, Marinelli RA. Glucagon induces the gene expression of aquaporin-8 but not that of aquaporin-9 water channels in the rat hepatocyte. Am J Physiol Regul Integr Comp Physiol 2009; 296: R1274-81.

37 Mei FC, Qiao J, Tsygankova OM, Meinkoth JL, Quilliam LA, Cheng X. Differential signaling of cyclic AMP: opposing effects of exchange protein directly activated by cyclic AMP and CAMP-dependent protein kinase on protein kinase B activation. J Biol Chem 2002; 277: 11497-504.

38 Kou R, Michel T. Epinephrine regulation of the endothelial nitric-oxide synthase: roles of RAC1 and beta3-adrenergic receptors in endothelial NO signaling. J Biol Chem 2007; 282: 32719-29.

39 Bellis A, Castaldo D, Trimarco V, Monti MG, Chivasso P, Sadoshima J, et al. Cross-talk between PKA and Akt protects endothelial cells from apoptosis in the late ischemic preconditioning. Arterioscler Thromb Vasc Biol 2009; 29: 1207-12. 